\title{
PUBLIC SCIENCE EDUCATION: ROLES AND CONTRIBUTIONS
}

Todar Lakhvich

Belarusian State Medical University, Republic of Belarus

\author{
Science is built up of facts as a house is of stones, but a collection of facts is \\ no more a science than a pile of stones is a house. \\ Henri Poincare, La Science et l'Hypothese (1908)
}

Why we need Science in our life? Why, when, and how people should learn scientific facts and acquire skills originated from application of specific scientific methods? Whether Science education is limited exclusively with the mission to prepare students to their life in the world of Physical/chemical/biological objects or vice versa it has a special cognitive potential that gives rise to the ability of every person regardless on its professional and social occupation to solve problems more effectively? JBSE publishes articles in which our authors try to answer all these questions exploring the issues of science education in different contexts. At the turn of the millennium, people have met a lot of new realities referring to issues in technologies, psychology, social relations etc. The life has changed drastically during a few last decades and a lot of traditional things seem to be perceived completely differently. How all those changes influenced the attitude to Science, how this is reflected in social and humanitarian issues, and finally, which ways should be proposed for Science Education in new reality?

Some experts, policy and public opinion makers focus the need for science education with only two roles: (i) Science and technology give opportunities for industrial and social development; (ii) for some students, it will become their professional occupation or/and a lifelong avocation. Nobody will argue with both roles: as the result University and high school syllabi and curricula for professional lines are mostly adequately structured and filled with the content (though, the introduction of the adequate and relevant educational technologies is the issue for special discussion). Based on this small-minded approach that narrows the role of science, education policy makers sometimes propose to limit the study of Science at pre-University School; the other tendency is to exclude definite disciplines (Physics, Biology, Chemistry, etc.) from secondary school curricula replacing them with integrated disciplines.

I dare to argue the aforementioned (in some countries very popular) tendency to exclude/integrate the definite "classical disciplines" from secondary school syllabi. For this I consider a few more and comprehensive roles of Science Education:

1. Science is evidently a part of human civilization development; it gives the methodology to digest facts via the experiment, reasoning, and discussion.

2. Science operates the scientific method that gives rise to the development of logics, problem-solving skills, complements the command of language, social communication, and etc.

3. When studying different Sciences, a person develops specific thinking skills involved in inquiry, experimentation, evidence evaluation, speculation argumentation, and finally, inference. 
4. Every Science discipline (the same with Humanities and arts) has its own epistemology, language, concept structure and specific modelling techniques. This means that by skipping the systematic study of one or more scientific disciplines, a person loses the opportunity to use specific ways of thinking that are characteristic of this area of knowledge.

5. Nowadays tendency to democracy and sustainable development requires that people were able to make personal and collective decisions based on reliable facts and/or expert assessment; the approach being typical for scientific method.

To dispute with exclusion/integration tendency, I will base on 5 comprehensive roles in modern society: three of them will be presented here and two more in the next issue. Evidently, editorial is not the format for fully systematic research, but I will try to address the issues that are related, in my opinion (and the opinion of experts, to which I will refer) with the lack and / or non-perception of science education in the culture of current society.

1. "All religions, arts, and sciences are branches from the same tree" (Einstein, 2006, p. 7). Such an attitude to human perception of the world has been reflected historically in the genesis of Education. Initially being integrated and holistic (from the traditions of Socrates and Aristotle), the Education was the lot of a few philosophers and humanitarians. That ancient and medieval period followed by the tendency of strong differentiation between disciplines, especially in the industrialization era. And finally, nowadays we meet again integration, but contrary to ancient period the connections are formed between the systematically formed fields of knowledge which are compulsory for all citizens. It means that a comprehensive and intertwined education is crucially important to prepare people for life, work, and civic participation.

It was mentioned previously that "recent science studies produced arguments for the thesis that sciences are also a cultural activity. As a consequence, Science and the related practices become time dependent - what was an accepted scientific practice in a particular period would not meet the standards of another period. Understanding science as a cultural activity poses several challenges to educators but offers also opportunities". (Heering, (2014).

Discussing the issue on the lower level we can mention that Science is piercing all our life and working properly in all the spheres of the society. And people are required to be equipped with scientific facts and scientific methods to be able to distinguish the reasoned facts vs opinions and beliefs; scientific finding vs testimony, etc. This is crucially important for sustainable development of democratic society of responsibly decision-making citizens.

2. It is worthy to argue against the utilitarian attitude to Science in Education (aka Science for needs: advanced level for future scientists; basic level for understanding facts about things we meet in life). I want to strengthen again the idea that Science education equips people with sufficient scientific skills to enable them to develop their activity in other than Science fields. And I have proved the argument in practice.

Stereochemistry is an important part of modern courses of Organic Chemistry. For decades (it has been introduced in university courses regularly about 70 years ago) the difficulties with student understanding and perception of stereochemistry have been discussed. But almost nobody and never proposed a reliable answer to the question "Why". More than two decades ago I wrote for the first time about the need of study of stereochemical concepts in secondary school (Lakhvich, 1997). Being a young scientist and educator, very cautious about conclusions and recommendation, I only stated that time the need of stereochemistry in the course of Organic chemistry taking in account the didactic principle of the continuity of education between different levels. Today I am confident in the unjustified absence of stereometric representations and training of spatial thinking in secondary (maybe even in primary) school. Obviously, syllabi and curricula can be different in other educational systems, but our conclusion about the lack of stereometric concepts in all the compulsory disciplines in Belarus seems to be reliable to other countries. In Belarus up to date Science Education is presented quite fully and comprehensively, wherein children study spatial concepts only in the courses of technical drawings (traditionally, the subject of the $3 \mathrm{~d}$ line) and geometry (chapter "Basics of stereometry" in 10th grade). In my opinion, people need to command skills of spatial thinking as it works within different fields of knowledge (e.g., the enhancement of the stereometric approach to analyzing economic categories and processes and investigating directions of its application in the science of security and taxation is discussed in terms of economic categories (Nusinov, 2019)).

Few years ago, I worked with international medical students who studied Bioorganic Chemistry within the framework of a special educational program (with some privileges in the recognition of diplomas and passing exams for postgraduate medical residency abroad) who graduated from medical colleges and Universities with some Biology lines. I met the older, a little bit experienced and very-very motivated students. In real, they were motivated to study those units they need either for passing some exams or for future medical activity. No doubt they were concerned why they needed to study stereochemistry. I tried to reply. "You need it to pass the exam; but first of 
all, this topic will enrich your professional thinking!". Then I took a presenter in my right hand and asked them to determine which side in relation to them I was holding the object. Evidently, they replied "on the left". Hereafter I made U-turn and repeated the same question. After a short silence, the process of the action comprehension has been reaching slowly their consciousness, the correct answer was received "on the right". Then, I pursued again, let's imagine you are doing surgery (no matter how: classically or endoscopically) and you need to reach some spot opposite to you...... The analogous to my first example situation regarding the need of developed spatial thinking. And immediately, one smart guy reflexed happily that he understood some topic in medicine after my examples on classes about stereochemistry.

Analogously, the study of stereometry in all Science disciplines requires the application of visualized models which are extremely important in the development of imaginary thinking. Drawing patterns are adaptive and suitable in any age group, when using the appropriate adjustments (Lakhvich, 2010, Locatelli, 2021).

3. Though we need to differentiate Science in practice and Science in Educational process, they will be concurrent in the technological context: the process of cognition proceeds in the analogous way. But objectives will be different. If briefly, "pure" Science is targeted to obtain NEW and reasoned facts (epistemology context) which are potentially profitable and applicable (social context). Science in Educational process is scheduled mostly to prepare students to life. This covers not only preparation for higher levels of education but also the development of general competences and skills (ability of being inquiring, initiative, creative, inventive, openness to new things) which are important in modern democratic society.

Scientific method is the core technology that relates Science in practice and Education. It was defined briefly and comprehensively as "a fixed four or five step procedure starting from observations and description of a phenomenon and progressing over formulation of a hypothesis which explains the phenomenon, designing and conducting experiments to test the hypothesis, analyzing the results, and ending with drawing a conclusion. Such references to a universal scientific method can be found in educational material at all levels of science education (Blachowicz, 2009).

Earlier we have discussed few principles which accommodate "pure" and teaching Science in such a way to take in account all procedural, psychological and didactic aspects of the educational process (Lakhvich, 2017): (i) To use only a few elements of research technology: the higher level of education the closer research structure; (ii) The experiments do not necessarily have to be absolutely innovative, the key point is a subjective novelty of the research for the students; (iii) The research primarily pursues educational and training rather than utilitarian objectives; (iv) Mostly modelling, rather than useless transferring the real problem situation of scientific research in student research, with the exception of expensive equipment and materials.

While putting aside the advanced educational lines for future scientists, we emphasize here once again that Science in education develops abilities that are useful to responsible citizens in modern society. That is why inquiry contributes to a critical attitude towards any fact. Instead of blind faith (television, social networks, politicians, a neighbor, etc.), a person analytically perceives information. At the same time, classical approaches are used that are characteristic of science: comparison, analysis, validation, reproducibility, variability, etc.

Ingenuity contributes to be active in all social initiatives. Openness to new things and variability give the more cognitive and consumption opportunities. Thus, most people experienced in scientific method tend to try new things, tastes, experience. They like travelling, degusting new meals. Some even say that scientists are overly amorous and have high sexuality. Contrary to the scientific method, I could not find confirmation of this fact in the scientific literature; in any case, science contributes much to person's wish to discover new facts in new things. Similarly, the ingenuity is the key to business development. And finally, scientists should accept all reasoned facts sometimes neglecting traditions of their society and correspondence to the ways they have been taught. And this feature is particularly important for a modern democracy to lead to a tolerant and respectful relationship between people. In cultivating diversity, tolerance creates conditions for a comfortable and safe life.

In this part of my consideration, I tried to show some general roles of Science Education in the development of human skills. Moreover, Science Education contributes much in the cultural environment of our civilization. It seems to me that readers of our journal will be interested to see studies that investigate these roles quantitatively. And we need more works on private subject didactics that suffered much from the lack of specialists in the field, enough experience both in science and methodology of educational research (Kubiatko, 2021).

For sure, the notion about the contribution on the cultural environment connects closely to ideology and strategy, society choices for development. The socio-cultural context is also closely connected with scientific and general literacy that prepare people for appropriate decision-making and ability to have "a critical and reflective 
view of the world" (Locatelli, 2021). If followed the tendency to democracy and sustainable development, the educational systems should foster broad-minded and responsible in their decision-making citizens who are able to make personal and collective decisions based on reliable facts and/or expert assessment; the approach being typical for scientific method. The latter will be discussed in the next issue, as well as the place of every Science discipline in the development of different thinking models. Altogether, Sciences prepare people for reasonable decision making in the modern society. But to gain the best result every Science should reveal its own and unique epistemology, language, concept structure and specific modelling techniques, Sciences will gain the best results in preparing people for reasonable decision making in the modern society. How it works I will try to show, the first, on the private example, where stereochemistry helps to train professional skills in future medical doctor's activity. The second, and more comprehensive example will touch the urgent issue of antivaxxers activity; I will try to discuss the role of Scientific method in the development of special skills to make personal and collective decisions based on reliable facts and/or expert assessment.

\section{References}

Blachowicz, J., (2009). How science textbooks treat scientific method: A philosopher's perspective. The British Journal for the Philosophy of Science, 60(2), 303-344. https://doi.org/10.1093/bjps/axp011

Einstein, A. (2006). The Einstein Reader. Citadel Press.

Heering, P. (2014). Scientific practices as cultural activities: A challenge and an opportunity for education. Journal of Baltic Science Education, 13(3), 296-297. http://www.scientiasocialis.lt/jbse/?q=node/361

Kubiatko, M. (2021). Subject didactics: Relevant issues. Problems of Education in the 21st Century, 79(3), $340-342$. https://dx.doi.org/10.33225/pec/21.79.340

Locatelli, S. W. (2021). Drawings to learn science: Some reflections. Problems of Education in the 21st Century, 79(2), 192-193. https://doi.org/10.33225/pec/21.79.192

Lakhvich, T. (1997). Study of basic stereochemistry concepts in secondary school. Chemistry: Educational Aspects (Khimia:prablemy vykladannia), 3(6), 3-19.

Locatelli, S. W. (2021). Reflecting upon fake news in today's post-truth era. Problems of Education in the 21st Century, 79(4), 513515. https://doi.org/10.33225/pec/21.79.513

Lakhvich, T. (2010). Beautylity of chemistry visualization: Whether useful can be aesthetic. Problems of Education in the 21st Century, 19, 46-50. http://www.scientiasocialis.lt/pec/node/356

Lahvich, T. (2017). Student research: Acquiring knowledge about the nature and process of science. Journal of Baltic Science Education, 16(6), 832-835. https://doi.org/10.33225/jbse/17.16.832

Nusinov, V., Mishchuk, I., \& Izmaylov, Y. (2019). Development of the stereometric method to the analysis of economic categories and processes and its application in security and taxation. Baltic Journal of Economic Studies, 5(4), 160-170. https://doi.org/10.30525/2256-0742/2019-5-4-160-170 